\title{
NIKOLAI NIKOLAEVICH DAVIDENKOV
}

Translated from Metallovedenie i Termicheskaya Obrabotka Metallov, No. 1, opposite p. 55, January, 1963

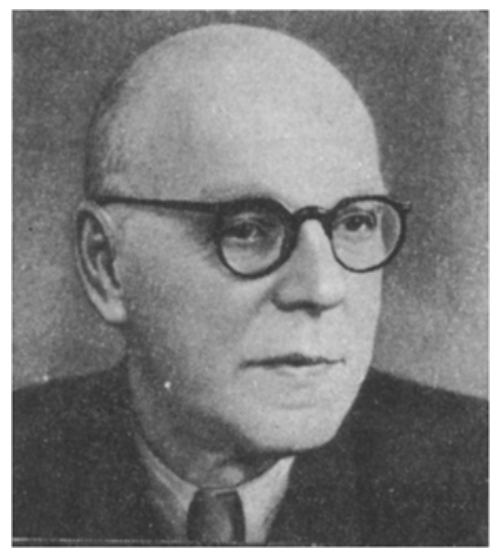

An outstanding Soviet scientist, Professor Nikolai Nikolaevich Davidenkov, Doctor of Technical Sciences, died suddenly on 29 September, 1962. He was director of the A. F. Ioffe Physicotechnical Institute, chairman of the department of physics of metals of the M. I. Kalinin Leningrad Polytechnical Institute, a winner of the State Prize, and a member of the Academy of Sciences, Ukr. SSR.

N. N. Davidenkov was bom in Riga in 1879. After finishing at Railroad Engineers Institute in 1909 he worked for seven years for the Russian railroads and at the same time taught strength of $\mathrm{m}$ aterials at the Petersburg Polytechnical Institute.

In 1925 he organized the department of physics of metals at the Leningrad Polytechnical Institute and the Laboratory of Mechanical Properties of the Physicotechnical Institute of the Academy of Sciences, USSR, which he directed until his death.

N. N. Davidenkov contributed greatly to the solution of problems in the strength, brittleness, and fatigue of metals, phenomena of nonlinear elasticity, creep, effect of the deformation rate on the mechanical properties of metals, tempering, residual stress, and many other problems.

He was a leader in the physics of metals and published over 200 articles and several monographs. During his fifty years of teaching at the Polytechnical Institute he educated many research engineers in the physics of metals. Many of his students became doctors and candidates of sciences.

N. N. Davidenkov was an active member of the editorial boards of several scientific journals and was an active industrial consult ant at the same time.

Up to the last days of his life he was full of ideas and projects which he generously shared with all those who came to him for help and advice.

The theoretical and practical work of N. N. Davidenkov has been recognized by the country. He has been awarded the Order of Lenin, the Order of the Red Flag of Labor, and several medals. In 1944 he was awarded the State Prize.

N. N. Davidenkov was an exceptional human being and full of life. Although he was very demanding, he gave everyone his attention, understanding, and warmth. He was considered a great authority, and his students and colleagues had deep respect and love for him.

All who met this remarkable scientist and human being will remember him forever. 